WS15-C01

\title{
Distributed Acoustic Borehole Seismic in Producing Offshore Wells
}

K.N. Norgaard Madsen* (Statoil ASA), M. Thompson (Statoil ASA), S. Dümmong (Statoil ASA), A. Kritski (Statoil ASA), A..S. Petersen (Statoil ASA), D. Finfer (Silixa) \& T. Parker (Silixa)

\section{SUMMARY}

Many Statoil operated wells are completed with fibre optic cables, typically installed for transmitting data from pressure/temperature gauges in the wells. The use of fibre optic cables for Distributed Acoustic Sensing (DAS) to acquire borehole seismic data in producing wells has been tested in a cooperation project between Silixa, Weatherford and Statoil, supported by Technology Strategy Board UK. Offshore field trials have been successfully carried out by retrofitting Silixa iDAS units to fibre optic cables previously installed in producing wells. Seismic signals were generated by a towed source and recorded by iDAS using the fibres in the wells as distributed sensors. The iDAS measurements were carried out without disturbing the normal operation of the wells, which were all producing during the acquisition of down hole seismic data.

The fibre optic cables used for the tests were installed strapped to tubing .i.e. without direct coupling to the formation. Even so, and in the presence of noise from production, it was possible to acquire seismic data with clear first arrivals from which travel times and interval velocities could reliably be obtained. Also reflected and refracted events are clearly visible. We will present results from DAS measurements in four producing offshore wells and discuss the potential of this exciting technology. 


\section{Amsterdam ' 14}

Many Statoil operated wells are completed with fibre optic cables, typically installed for transmitting data from pressure/temperature gauges in the wells. The use of fibre optic cables for Distributed Acoustic Sensing (DAS) to acquire borehole seismic data in producing wells has been tested in a cooperation project between Silixa, Weatherford and Statoil, supported by Technology Strategy Board UK. Offshore field trials have been successfully carried out by retrofitting Silixa iDAS units to fibre optic cables previously installed in producing wells. Seismic signals were generated by a towed source and recorded by iDAS using the fibres in the wells as distributed sensors. The iDAS measurements were carried out without disturbing the normal operation of the wells, which were all producing during the acquisition of down hole seismic data.

The fibre optic cables used for the tests were installed strapped to tubing .i.e. without direct coupling to the formation. Even so, and in the presence of noise from production, it was possible to acquire seismic data with clear first arrivals from which travel times and interval velocities could reliably be obtained. Also reflected and refracted events are clearly visible. We will present results from DAS measurements in four producing offshore wells and discuss the potential of this exciting technology. 